\title{
Detection and surveillance of viral hemorrhagic septicemia virus using real-time RT-PCR. II. Diagnostic evaluation of two protocols
}

\author{
Janet V. Warg ${ }^{1, *}$, Travis Clement ${ }^{2}$, Emily R. Cornwell ${ }^{3}$, Angela Cruz ${ }^{1}$, \\ Rodman G. Getchell ${ }^{3}$, Cem Giray ${ }^{4}$, Andrew E. Goodwin ${ }^{5}$, Geoffrey H. Groocock ${ }^{3}$, \\ Mohamed Faisal ${ }^{6}$, Robert Kim ${ }^{6}$, Gwenn E. Merry ${ }^{5}$, Nicholas B. D. Phelps ${ }^{7}$, Monica \\ M. Reising ${ }^{8}$, Isaac Standish ${ }^{6}$, Yan Zhang ${ }^{9}$, Kathy Toohey-Kurth ${ }^{10}$ \\ ${ }^{1}$ Diagnostic Virology Laboratory, National Veterinary Services Laboratories, VS, APHIS, USDA, Ames, Iowa 50010, USA \\ ${ }^{2}$ Animal Disease Research and Diagnostic Laboratory, South Dakota State University, Brookings, South Dakota 57006, USA \\ ${ }^{3}$ Aquatic Animal Health Program, Department of Microbiology and Immunology, Cornell University, Ithaca, \\ New York 14853, USA \\ ${ }^{4}$ Kennebec River Biosciences, Richmond, Maine 04357, USA \\ ${ }^{5}$ Aquaculture/Fisheries Center, University of Arkansas Pine Bluff, Pine Bluff, Arkansas 71601, USA \\ ${ }^{6}$ Aquatic Animal Health Laboratory, College of Veterinary Medicine, Michigan State University, \\ East Lansing, Michigan 48824, USA \\ ${ }^{7}$ Veterinary Diagnostic Laboratory, University of Minnesota, St. Paul, Minnesota 55108, USA \\ ${ }^{8}$ Center for Veterinary Biologics, VS, APHIS, USDA, Ames, Iowa 50010, USA \\ ${ }^{9}$ Animal Disease Diagnostic Laboratory, Ohio Department of Agriculture, Reynoldsburg, Ohio 43068, USA \\ ${ }^{10}$ Wisconsin Veterinary Diagnostic Laboratory, University of Wisconsin, Madison, Wisconsin 53706, USA
}

\begin{abstract}
Two real-time reverse transcription polymerase chain reaction (rRT-PCR) assays under consideration for deployment to multiple testing laboratories across the USA were evaluated for diagnostic sensitivity and specificity on tissue homogenates obtained from natural and experimental viral hemorrhagic septicemia (VHS)-infected fish. Estimates for diagnostic specificity using virus isolation as the reference method were similar between laboratories regardless of the assay. Diagnostic sensitivity estimates of 0.96 (95\% CI: 0.95, 0.97) for Jonstrup et al. (2013)'s assay ( $J$ Fish Dis 36:9-23) exceeded the diagnostic sensitivity of 0.85 (95\% CI: 0.83, 0.87) for Phelps et al. (2012)'s assay ( $J$ Aquat Anim Health 24:238-243). The Jonstrup rRT-PCR assay is robust as demonstrated by high sensitivity and specificity estimates across laboratories and can be used as a valuable tool for targeted surveillance and for testing of suspect VHSV samples.
\end{abstract}

KEY WORDS: VHSV - Surveillance $\cdot$ Real-time RT-PCR $\cdot$ Diagnostic sensitivity $\cdot$ Diagnostic specificity

\section{INTRODUCTION}

Rapid and precise detection of viral hemorrhagic septicemia virus (VHSV) is important for disease prevention and containment by reducing the risk of spread or movement from an infected zone or compartment. Currently, the internationally accepted method for diagnostic, surveillance, and confirmation testing is virus isolation from fish tissue specimens performed on bluegill fry (BF-2), epithe- 
lioma papulosum cyprini (EPC), and fathead minnow (FHM) cell cultures with follow-up antibody or nucleic acid based virus identification (OIE 2009). Multiple real-time reverse transcription polymerase chain reaction (rRT-PCR) assays have been developed in order to reduce the amount of time required to obtain a test result. The use of rRTPCR as a robust targeted surveillance and diagnostic tool is becoming more widely accepted in both aquatic and terrestrial animal health management.

In the USA, VHSV genotype IVa is documented in fish collected from waters in the Pacific Northwest (Hershberger et al. 2010), while VHSV genotype IVb is documented in fish collected from the waters of the Laurentian Great Lakes (Faisal et al. 2012). Many other regions or watersheds in the USA are free from VHSV. The emergence of VHSV IVb in the Laurentian Great Lakes of North America triggered intense surveillance efforts and disease investigations, and VHSV is now considered enzootic in these wild fish populations. Similarly, VHSV is often considered enzootic in the Pacific Northwest, even though the actual disease incidences are unknown. VHSV represents a serious risk to farmed or managed fish populations within the Great Lakes watershed and the Pacific Northwest. In addition, dissemination risks are a consideration when moving fish from these areas to other regions within or outside of the USA (Gustafson et al. 2010, VHSV Expert Panel and Working Group 2010). A rapid and high-throughput diagnostic assay would be extremely useful for controlling VHSV and for facilitating fish trade. However, as testing for VHSV occurs in state, federal, and private laboratories located across the USA and this information is used for disease management, risk analysis, and regulatory purposes, it is imperative to adopt a standardized testing protocol.

In this manuscript, we report on a collaborative side-by-side evaluation of the TaqMan ${ }^{\circledR}$ based assay developed by Jonstrup et al. (2013; hereafter 'Jonstrup assay') and the 1-step format of Phelps et al. (2012; 'Phelps assay') that utilizes primers and probe developed by Garver et al. (2011) in an effort to estimate the diagnostic sensitivity and specificity of each test procedure. The 2 assays were selected based on a comparison of analytical performance of 4 assays (Warg et al. 2014, this volume). Eight laboratories evaluated a tissue panel that contained 200 VHSV virus isolation positive and $200 \mathrm{VHSV}$ virus isolation negative tissue homogenate supernatants using standardized rRT-PCR testing protocols.

\section{MATERIALS AND METHODS}

\author{
Fish samples
}

VHSV IVa experimentally infected fish

VHSV IVa-injected specific pathogen free Pacific herring Clupea pallasii were provided by Dr. Paul Hershberger. Infected fish were euthanized at $12 \mathrm{~d}$ post exposure, and the kidney and spleen were removed for a different study (Hershberger et al. 2010). The incision on the fish was closed and the fish was placed in a bag. The fish were stored frozen at $-80^{\circ} \mathrm{C}$. Frozen fish for processing into whole body homogenates were shipped on dry ice to the National Veterinary Services Laboratories (NVSL).

\section{VHSV IVb wild fish samples}

Fish collected as part of a Great Lakes 2010 surveillance effort (E. R. Cornwell et al. unpubl.) were utilized for this study. Tissues (anterior kidney, posterior kidney, spleen, heart, and liver) in $2 \mathrm{ml}$ homogenizing tubes were shipped on frozen gel packs or dry ice to the NVSL.

\section{VHSV IVb experimentally infected fish}

VHSV IVb-injected and exposed fish were provided by Dr. A. E. Goodwin. Briefly, largemouth bass Micropterus salmoides, bluegill Lepomis macrochirus, channel catfish Ictalurus punctatus, and grass carp Ctenopharyngodon idella were sorted into tanks by species (bluegill were further sorted by size into 2 tanks). Inoculated fish received an intraperitoneal injection of VHSV IVb $\left(1 \times 10^{6} \mathrm{TCID}_{50}\right.$ per ml $)$ and were maintained at $12{ }^{\circ} \mathrm{C}$ with non-injected fish. All fish in a treatment group were euthanized with MS222 when the first non-injected cohabitant died (an indication of horizontal spread to tank cohabitants). Spleen, kidney, and brain samples were collected, placed in Whirl-Pak ${ }^{\circledR}$ bags and immediately frozen at $\leq-80^{\circ} \mathrm{C}$. Tissues were shipped on dry ice to the NVSL.

\section{VHSV negative fish}

VHSV negative fish included fish collected from natural water bodies, experimental studies, and diagnostic case submissions. Fish from natural water 
bodies outside of the Great Lakes were collected during regional VHSV surveillance efforts. Some of the negative fish samples contained other known pathogens, specifically fathead minnow nidovirus and koi herpesvirus (Table 1).

\section{Tissue panel preparation}

All samples were initially tested for VHSV by virus isolation in cell culture at the NVSL prior to inclusion in the test panel (Table 1). Tissue homogenate supernatants were prepared according to the OIE manual (OIE 2009). Briefly, fish tissues were homogenized in Dulbecco's modified Eagle's cell culture medium

Table 1. Tissue panel samples. FHMNV: fathead minnow nidovirus; KHV: koi herpesvirus

\begin{tabular}{|c|c|c|c|}
\hline Sample number(s) & $\begin{array}{l}\text { Common } \\
\text { name }\end{array}$ & $\begin{array}{l}\text { Single fish } \\
\text { or pool }\end{array}$ & Source \\
\hline \multicolumn{4}{|l|}{ Positive samples } \\
\hline $\begin{array}{l}1-24,26-36,40 \\
\quad 45-62\end{array}$ & Round goby & Single & Wild Great Lakes \\
\hline 38,44 & Yellow perch & Single & Wild Great Lakes \\
\hline $39,41,42$ & Rock bass & Single & Wild Great Lakes \\
\hline 43 & Pumpkinseed & Single & Wild Great Lakes \\
\hline 25 & Smallmouth bass & Single & Wild Great Lakes \\
\hline 37 & Bluegill & Single & Wild Great Lakes \\
\hline $66,70,73$ & Bluegill & Pool of 2 & Exp IVb -contact \\
\hline $\begin{array}{l}63-65,67-69 \\
\quad 71,72,74-101\end{array}$ & Bluegill & Single & Exp IVb -contact \\
\hline $102-110$ & Largemouth bass & Single & Exp IVb -contact \\
\hline 111-119 & Channel catfish & Single & Exp IVb -contact \\
\hline $120-123,136-139$ & Muskellunge & Single & Injected exp IVb \\
\hline $124-130$ & Muskellunge & Pool of 2 & Injected exp IVb \\
\hline $131-132$ & Muskellunge & Pool of 3 & Injected exp IVb \\
\hline 133 & Muskellunge & Pool of 4 & Injected exp IVb \\
\hline $134-135$ & Muskellunge & Pool of 5 & Injected exp IVb \\
\hline $140-200$ & Pacific herring & Single & Injected exp IVa \\
\hline \multicolumn{4}{|l|}{ Negative samples } \\
\hline 201 & Largemouth bass & Pool of 5 & Exp neg control \\
\hline 202 & Bluegill & Pool of 5 & Exp neg control \\
\hline 203 & Bluegill & Pool of 5 & Exp neg control \\
\hline 204 & Channel catfish & Pool of 5 & Exp neg control \\
\hline 205 & Channel catfish & Pool of 3 & Exp neg control \\
\hline 206-207 & Grass carp & & Exp neg control \\
\hline $208-257$ & Pacific herring & Single & Exp neg control \\
\hline $258-280$ & Fathead minnow & Single & Injected exp FHMNV \\
\hline 281 & Koi & Single & KHV positive \\
\hline $282-381$ & Walleye & Pool of 5 & Wild fish negative \\
\hline $382-383$ & Smallmouth bass & Pool of 5 & Wild fish negative \\
\hline 384 & Rock bass & Pool of 5 & Wild fish negative \\
\hline $385-393$ & Yellow perch & Pool of 5 & Wild fish negative \\
\hline 394 & Hybrid bluegill & Pool of 5 & Wild fish negative \\
\hline $395-396$ & Bluegill & Pool of 5 & Wild fish negative \\
\hline 397-398 & Largemouth bass & Pool of 5 & Wild fish negative \\
\hline $399-400$ & Fathead minnow & Pool of 5 & Wild fish negative \\
\hline
\end{tabular}

supplemented with $2.5 \%$ fetal bovine serum, antibiotics, 4.0 mM L-glutamine, 0.006 M sodium bicarbonate, $2 \mathrm{mM}$ sodium pyruvate, and $0.02 \mathrm{M} \mathrm{HEPES}$ at a final dilution of $1 / 10$. Homogenates were centrifuged at 2000 to $4000 \times g\left(15 \mathrm{~min}\right.$ at $\left.4 \pm 3^{\circ} \mathrm{C}\right)$. Tissue homogenate supernatants were inoculated onto confluent EPC cell cultures and observed regularly for virusinduced cytopathic effects (CPE). When CPE were observed, virus identification by PCR amplification (Hedrick et al. 2003) and direct sequencing of the amplicon were performed. Positive samples selected were observed to induce $\mathrm{CPE}$, and sequencing confirmed the presence of VHSV. Inoculated cultures lacking CPE were sub-cultured 7 to $14 \mathrm{~d}$ after inoculation. Subcultures were observed for 14 to $21 \mathrm{~d}$.

Samples were considered negative when no CPE were observed in the secondary cultures. Tissue homogenates were stored in an ultralow freezer $\left(\leq-65^{\circ} \mathrm{C}\right)$ until aliquoted into panels.

Ten sets containing the numbers 1 to 400 were scrambled using the RAND function and sorting in Microsoft ${ }^{\circledR}$ EXCEL in order to generate tissue sets that lacked any pattern. Each sample in the test panel was assigned a set number and sample number for comparison to the expected result key. Some tissue homogenates were pooled by species in order to have sufficient sample for testing by all laboratories. The negative tissue homogenates were thawed first and centrifuged, and $0.125 \mathrm{ml}$ of the supernatant aliquoted into appropriately labeled tubes and immediately refrozen in boxed sets. Positive tissue homogenates were thawed second and aliquoted in the same manner. Panels were shipped to participating laboratories on dry ice. Virus isolation was repeated on tissue homogenates when thawed for dispensing into aliquots.

\section{RNA extraction and real-time RT-PCR}

Each tissue homogenate was extracted 1 time by participating labs using the MagMAX ${ }^{\mathrm{TM}}$-96 Viral RNA Isolation Kit (Ambion ${ }^{\circledR}$ kit AM1836, 
Life Technologies) using either an automated or manual system. The automated and manual extraction processes provide consistent nucleic acid yields (Shah et al. 2009). The same RNA extracted from each tissue homogenate sample was evaluated by both rRT-PCR assays. Both assays use a 1-step approach with different pan-VHSV primers and probes that target the nucleoprotein. Laboratories followed standardized testing protocols supplied to all participants. Detailed information on each assay can be found in Jonstrup et al. (2013) and Phelps et al. (2012). Briefly, for the Jonstrup assay a $25 \mu \mathrm{l}$ reaction mixture contained the Quantitect RT-PCR Buffer and RTPCR Enzyme (Qiagen), FAM-labeled TaqMan probe (5'-6-FAM-TAG AGG GCC TTG GTG ATC TTC TGBHQ1), primers (5'-AAA CTC GCA GGA TGT GTG CGT CC-3' and 5'-TCT GCG ATC TCA GTC AGG ATG AA-3'), and the RNA sample. The thermal cycling protocol consisted of $30 \mathrm{~min}$ at $50^{\circ} \mathrm{C}, 15 \mathrm{~min}$ at $95^{\circ} \mathrm{C}$, followed by 40 cycles of $15 \mathrm{~s}$ at $94^{\circ} \mathrm{C}, 40 \mathrm{~s}$ at $60^{\circ} \mathrm{C}$, and $20 \mathrm{~s}$ at $72^{\circ} \mathrm{C}$. For the Phelps assay, a $25 \mu \mathrm{l}$ reaction mixture contained Path-ID Multiplex RTPCR buffer and Path-ID Multiplex enzyme mix (Life Technologies), FAM-labeled MGB Probe (5'-FamTAC GCC ATC ATG ATG AGT- 3'), primers (5'-ATG AGG CAG GTG TCG GAG G-3' and 5'-TGT AGT AGG ACT CTC CCA GCA TCC-3'), and the RNA sample. The thermal cycling protocol consisted of $10 \mathrm{~min}$ at $45^{\circ} \mathrm{C}, 10 \mathrm{~min}$ at $95^{\circ} \mathrm{C}$, followed by 40 cycles of $15 \mathrm{~s}$ at $95^{\circ} \mathrm{C}$ and $60 \mathrm{~s}$ at $60^{\circ} \mathrm{C}$.

Laboratories ('Labs') participating in this comparison had different levels of high-throughput or rRTPCR testing experience (Table 2 in Warg et al. 2014) ranging from extensive experience (high) to limited experience (recently trained). In Labs A, D, and E, personnel were experienced with high-throughput testing and with conducting rRT-PCR. In Labs B and $\mathrm{H}$, personnel were experienced with large numbers of samples and with conventional RT-PCR, but were recently trained to perform real-time assays. Labs $C$ and $G$ have dual roles as both diagnostic and research laboratories with some experience with both high-throughput testing and rRT-PCR. Lab F also has dual function being involved in both research and diagnostics; in this laboratory, the technicians were recently trained in high-throughput testing and to perform real-time assays. Specific realtime PCR machines and software used in this study (Table 2 in Warg et al. 2014) included the ABI 7500 software version 1.4 or software version 2.0 (ABI, Life Technologies), BioRad iCycler iQ ${ }^{\mathrm{TM}}$ software version 3.1 (BioRad), and Mastercycle ${ }^{\circledR}$ EP Realplex software version 1.5 or software version 2.2 (Eppendorf).
Data analysis parameters were standardized (Warg et al. 2014). Briefly, the auto Ct algorithm was utilized to set the baseline and threshold parameters for ABI platforms and software. If the baseline was set too low (higher background on a run), a second analysis was performed using auto threshold and manual baseline settings ( 3 to 15 cycles). The Auto Ct algorithm was used for the BioRad iCycler iQ ${ }^{\mathrm{TM}}$ software version 3.1. For the Mastercycler ${ }^{\circledR}$ EP Realplex software version 1.5, the best-fit algorithm was used to set the baseline and threshold. Thresholds were manually established for the Mastercycler ${ }^{\circledR}$ EP Realplex software version 2.2 based on a set percentage of the plateau of the low positive amplification control.

\section{Diagnostic sensitivity, specificity, and reproducibility}

Diagnostic sensitivity (DSe) and specificity (DSp) estimates using virus isolation as the 'true' infection status were estimated. A sample was classified as PCR positive if a cycle threshold $(\mathrm{Ct})$ value was produced. A generalized linear model with a logit link (McCullagh \& Nelder 1989) was fit to the number of correct test results (across laboratories) for each sample. An estimate of the mean, $\mu$, was used to determine the sensitivity (or specificity) as $1 /$ [ $1+$ $\exp (-\mu)]$. Confidence intervals were obtained using the delta method. Qualitative test results (positive or negative) for each sample were aligned to gauge the agreement of the test result for the same assay on the same sample in different laboratories. Ct values from positive amplification controls were used to monitor assay performance.

\section{RESULTS}

\section{Diagnostic sensitivity}

The percentages of correct positive classifications by laboratory for the portion of positive tissue homogenates that tested positive were calculated (Table 2). Out of the 200 samples positive by virus isolation for VHSV, 185 to 199 tested positive by the Jonstrup assay and 128 to 196 tested positive by the Phelps assay. Sensitivity was estimated to be 0.96 (95\% CI: $0.95,0.97)$ for the Jonstrup assay and 0.85 (95\% CI: 0.83, 0.87) for the Phelps assay. Test results were aligned (Fig. 1) to evaluate whether any particular samples produced false negative test 
Table 2. Percentage of correct classifications by laboratory. VI: virus isolation reference standard: DSe (\%): diagnostic sensitivity; DSp (\%): diagnostic specificity

\begin{tabular}{|c|c|c|c|c|c|c|}
\hline $\begin{array}{l}\text { Method } \\
\text { Lab }\end{array}$ & $\begin{array}{c}\mathrm{VI}+/ \\
\mathrm{PCR}+\end{array}$ & $\begin{array}{l}\mathrm{VI}+/ \\
\mathrm{PCR}-\end{array}$ & $\begin{array}{l}\mathrm{VI}-/ \\
\mathrm{PCR}+\end{array}$ & $\begin{array}{l}\mathrm{VI}-/ \\
\mathrm{PCR}-\end{array}$ & $\begin{array}{l}\text { DSe } \\
(\%)\end{array}$ & $\begin{array}{l}\text { DSp } \\
(\%)\end{array}$ \\
\hline \multicolumn{7}{|c|}{ Jonstrup et al. (2013) } \\
\hline A & 196 & 5 & 0 & 200 & 97.5 & 100.0 \\
\hline B & 198 & 2 & 0 & 200 & 99.0 & 100.0 \\
\hline $\mathrm{C}$ & 191 & 9 & 8 & 192 & 95.5 & 96.0 \\
\hline $\mathrm{D}$ & 196 & 4 & 0 & 200 & 98.0 & 100.0 \\
\hline E & 199 & 1 & 0 & 200 & 99.5 & 100.0 \\
\hline $\mathrm{F}$ & 190 & 10 & 26 & 174 & 95.0 & 87.0 \\
\hline G & 188 & 12 & 3 & 197 & 94.0 & 98.5 \\
\hline $\mathrm{H}$ & 185 & 15 & 12 & 188 & 92.5 & 94.0 \\
\hline \multicolumn{7}{|c|}{ Phelps et al. (2012) } \\
\hline $\mathrm{A}$ & 173 & 27 & 0 & 200 & 86.5 & 100.0 \\
\hline B & 196 & 4 & 0 & 200 & 98.0 & 100.0 \\
\hline $\mathrm{C}$ & 128 & 71 & 2 & 197 & 64.3 & 99.0 \\
\hline D & 188 & 12 & 0 & 198 & 94.0 & 100.0 \\
\hline E & 165 & 35 & 0 & 200 & 82.5 & 100.0 \\
\hline $\mathrm{F}$ & 178 & 22 & 0 & 200 & 89.0 & 100.0 \\
\hline $\mathrm{G}$ & 144 & 56 & 0 & 200 & 72.0 & 100.0 \\
\hline $\mathrm{H}$ & 188 & 12 & 16 & 184 & 94.0 & 92.0 \\
\hline
\end{tabular}

results in multiple laboratories. Three samples (3, 108, and 116) were reported as false negatives when evaluated by the Jonstrup assay by most laboratories. Other samples with false negative results reported by 2 or more laboratories included sample 77 (4 laboratories), samples 70 and 81 (3 laboratories), and samples 65, 71, 94, 138 and 160 (2 laboratories). False negative results were reported for both VHSV IVa (5 samples) and VHSV IVb (24 samples). The number of injected VHSV IVb $(2$ samples) false negative samples was similar to the number of injected IVa (5 samples) false negative samples. The remaining VHSV IVb false negative samples included 7 natural infection and 15 experimental infection contact animals. An additional 18 samples were reported as false negative by a single laboratory. The number of virus isolation positive samples with false negative reports when evaluated by the Phelps assay was high (79 samples had at least 1 laboratory reporting them as false negative) as compared to the Jonstrup assay (29 samples). Samples 3, 108, and 116 were also reported as false negatives by the Phelps assay.

\section{Diagnostic specificity}

The percentages of negative classifications by laboratory for the portion of negative tissue homogenates that tested negative were calculated
(Table 2). Out of the 200 samples negative by virus isolation for VHSV, 174 to 200 tested negative by the Jonstrup assay and 184 to 200 by the Phelps assay. Specificity was estimated to be 0.97 (95\% CI: $0.97,0.98)$ for the Jonstrup assay and $0.99(95 \%$ CI: $0.98,0.99$ ) for the Phelps assay. Four laboratories (A, B, D, and E) reported no false positive test results for either assay. False positive results included both low and high Ct values. No single sample was reported as false positive by multiple laboratories. Two labs ( $\mathrm{F}$ and $\mathrm{H}$ ) reported the majority of false positives for the Jonstrup assay; a single lab (H) had the majority of false positives for the Phelps assay. Lab $\mathrm{H}$ also experenced a high number of false negatives with the Jonstrup assay.

\section{DISCUSSION}

The objective of this study was to evaluate (side by side) the diagnostic performance of 2 assays under consideration for deployment to a network of independent laboratories that provide surveillance, diagnostic, and fish facility monitoring testing for VHSV. The tissue samples utilized in this comparison were selected to closely match the types of samples a diagnostic laboratory might receive for routine testing in terms of species, sample matrix, attribute being measured, and target concentrations. In order to reduce but not eliminate inhomogeneity and instability concerns, tissue homogenate supernatants were selected as the testing matrix. Extensive homogeneity and stability testing was not possible due to sample size limitations. However, in such cases the use of this type of sample is still useful as long as this uncertainty is considered during the evaluation of results (ISO 2010).

Estimates of diagnostic sensitivity and specificity from this study are most likely biased as the true classification for each sample is based on an imperfect test. The trueness of the classification does not preclude comparing assay performance across laboratories on these samples. Further, the reference test is detecting infectious virus, while the PCR assays detect the presence of nucleic acid. The performance (robustness) of the assays was compared across the laboratories using the percentage of samples with 
(A) Jonstrup et al. (2013)

$\begin{array}{ll}\text { VI } \\ \text { Lab } & \text { B } \\ \text { Lab } & \text { E } \\ \text { Lab } & \text { A } \\ \text { Lab } & \text { C } \\ \text { Lab } & \text { D } \\ \text { Lab } & \text { F } \\ \text { Lab } & \text { G } \\ \text { Lab } & \text { H } \\ \text { VI } & \\ \text { Lab } & \text { B } \\ \text { Lab } & \text { E } \\ \text { Lab } & \text { A } \\ \text { Lab } & \text { C } \\ \text { Lab } & \text { D } \\ \text { Lab } & \text { F } \\ \text { Lab } & \text { G } \\ \text { Lab } & \text { H } \\ \text { VI } & \\ \text { Lab } & \text { B } \\ \text { Lab } & \text { E } \\ \text { Lab } & \text { A } \\ \text { Lab } & \text { C } \\ \text { Lab } & \text { D } \\ \text { Lab } & \text { F } \\ \text { Lab } & \text { G } \\ \text { Lab } & \text { H } \\ \text { VI } & \\ \text { Lab } & \text { B } \\ \text { Lab } & \text { E } \\ \text { Lab } & \text { A } \\ \text { Lab } & \text { C } \\ \text { Lab } & \text { D } \\ \text { Lab } & \text { F } \\ \text { Lab } & \text { G } \\ \text { Lab } & \text { H }\end{array}$

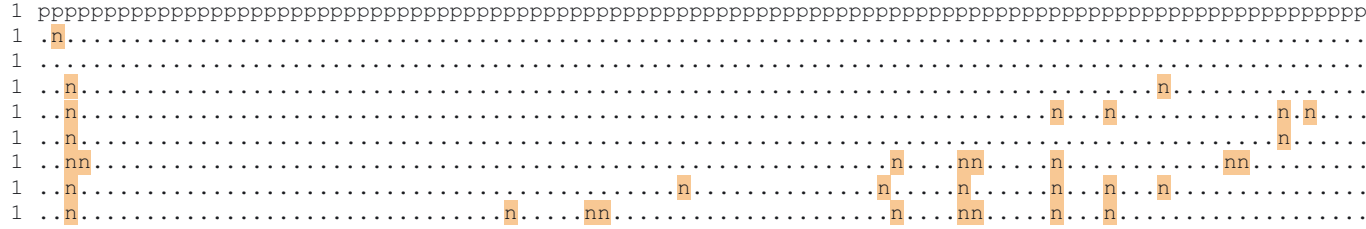

101 pppppppppppppppppppppppppppppppppppppppppppppppppppppppppppppppppppppppppppppppppppppppppppppppppp
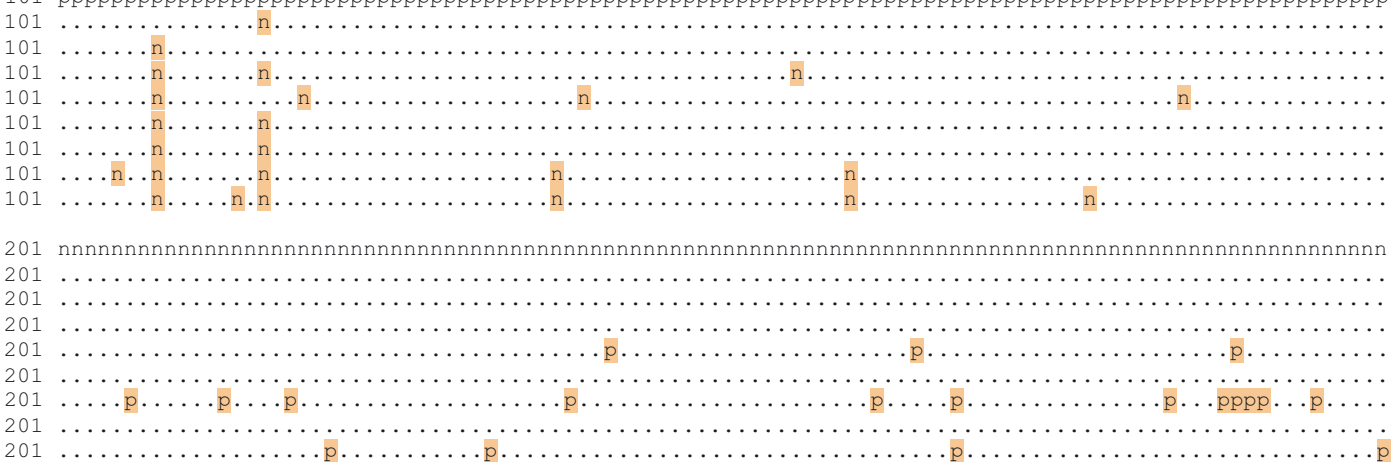

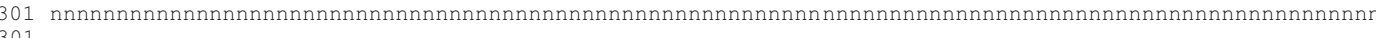
301

301

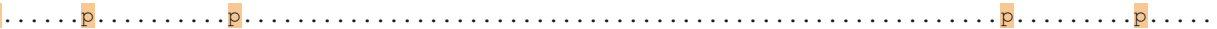

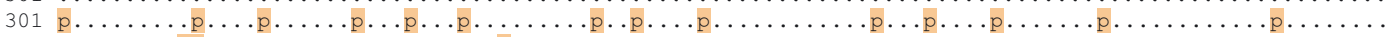

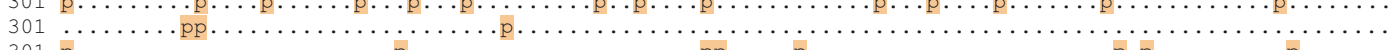

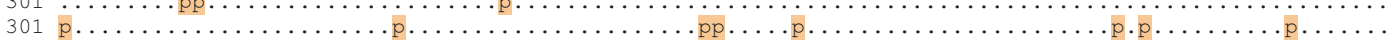

\section{(B) Phelps et al. (2012)}

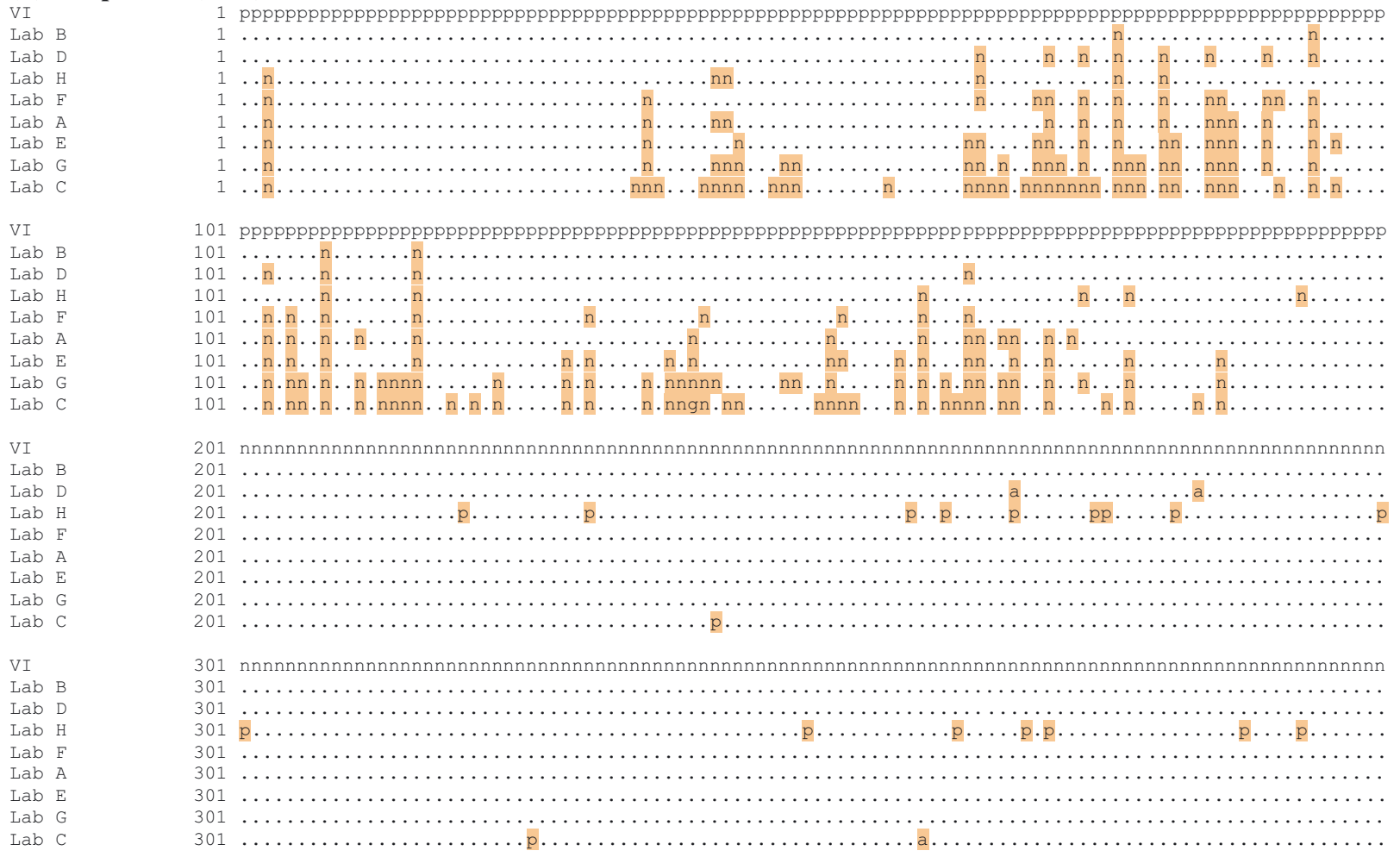

Fig. 1. Alignment of VHSV rRT-PCR test results for (A) Jonstrup et al. (2013) and (B) Phelps et al. (2012) assays by testing laboratory to evaluate whether any particular sample had false test results across laboratories: VI: virus isolation reference standard; p: positive results; n: negative result; a: aberrant curve (test result not considered in calculating estimates). Test results in agreement with the reference standard (virus isolation) are indicated by a dot 
the correct classification. This comparison is also impacted by inherent biases which are identical for all 8 laboratories. Therefore, a comparison of the 2 different rRT-PCR assays performance on the same tissue panel by testing laboratories is not likely to be impacted by these particular inherent biases. In this multi-laboratory evaluation of rRT-PCR assays for VHSV detection, the Jonstrup assay (Jonstrup et al. 2013) outperformed the Phelps assay (Phelps et al. 2012) for diagnostic sensitivity, but assay performances were similar for diagnostic specificity.

The Phelps assay is a modification of the Garver et al. (2011) VHSV rRT-PCR 2-step assay to a 1-step approach (Phelps et al. 2012). Diagnostic sensitivity estimates for the Phelps assay of $<90 \%$ by 5 out of the 8 participating laboratories was lower than expected based on analytical published data of Phelps et al. (2013) and comparisons of the limit of detection (LOD) on representative isolates from each genotype of VHSV for this assay (Warg et al. 2014). A comparison of analytical sensitivity for the Phelps assay and the Garver assay reported similar LODs (Warg et al. 2014). However, efficiency estimates for the Phelps assay (102-151\% on VHSV MI03 RNA standards) were suboptimal (optimal being 90-104\%).

Virus isolation is an imperfect standard, and this was taken into consideration when assigning the infection status of a sample and evaluating assay comparison data (Fig. 1). Virus isolation was repeated on all tissue homogenate supernatants when thawed for aliquoting into the test panels. Virus was recovered from 134 of the 200 samples that originally tested positive for VHSV. This is not unexpected as material frozen (whole fish, tissue homogenate, or supernatant) and freeze-thaw events can impact the ability to recover replicating virus from a diagnostic sample (Meyers et al. 1999, Arkush et al. 2006, Hervé-Claude et al. 2008), but have less impact on the ability to detect viral RNA (Phelps et al. 2013). All 200 negative samples tested negative on repeat virus isolation testing. Samples 3, 108, and 116 showed 'false negative' results with both PCR assays (Fig. 1) in multiple but not all laboratories. Samples 108 (largemouth bass) and 116 (channel catfish) were both fish cohabited in tanks with injected fish (Table 1) and were negative for virus isolation on repeat testing. Sample 3 was a naturally infected round goby that was positive for virus isolation on repeat testing. False negative PCR results were obtained by the Jonstrup assay for 6 cohabitant bluegill (samples 65, 70, 71, 77, 81, 84) and 2 injected fish (muskellunge 138 and herring 160); these samples were negative for virus isolation on repeat test- ing. Samples reported as false negative by the Phelps assay included wild, cohabitants, and injected fish. False positive classification is equally a concern. The number of false positives was low by both assays. Sample history and a review of samples testing false positive do not suggest misclassification of infection status.

On the basis of this study, the rRT-PCR assay of Jonstrup et al. (2013) can be used as a valuable tool when surveillance or suspect VHSV samples are submitted to a laboratory for testing. In addition, the high throughput capacity and the speed of the assay will allow rapid identification of VHSV affected farms or populations.

Acknowledgements. We thank Søren Jonstrup, formerly of the Section for Fish Diseases, National Veterinary Institute (Denmark), for sharing his testing protocols prior to publication; Paul Hershberger of the Marrowstone Marine Field Station, United States Geological Survey, for providing VHSV IVa positive tissues; and Mary Lea Killian of the Diagnostic Virology Laboratory, National Veterinary Services Laboratories, and Gael Kurath of the USGS Western Fisheries Research Center, for helpful discussions. This work was funded by USDA. Any use of trade, firm, or product names is for descriptive purposes only and does not imply endorsement by the US Government.

\section{LITERATURE CITED}

Arkush KD, Mendonca HL, McBride AM, Yun S, McDowell TS, Hedrick RP (2006) Effects of temperature on infectivity and of commercial freezing on survival of the North American strain of viral hemorrhagic septicemia virus (VHSV). Dis Aquat Org 69:145-151

Faisal M, Shavalier M, Kim RK, Millard EV and others (2012) Spread of the emerging viral hemorrhagic septicemia virus strain, genotype IVb, in Michigan, USA. Viruses 4: 734-760

> Garver KA, Hawley LM, McClure CA, Schroeder T and others (2011) Development and validation of a reverse transcription quantitative PCR for universal detection of viral hemorrhagic septicemia virus. Dis Aquat Org 95: 97-112

> Gustafson L, Klotins K, Tomlinson S, Karreman G and others (2010) Combining surveillance and expert evidence of viral hemorrhagic septicemia freedom: a decision science approach. Prev Vet Med 94:140-153

Hedrick RP, Batts WN, Yun S, Traxler GS, Kaufman J, Winton JR (2003) Host and geographic range extensions of the North American strain of viral hemorrhagic septicemia virus. Dis Aquat Org 55:211-220

Hershberger PK, Gregg JL, Grady CA, Taylor L, Winton JR (2010) Chronic and persistent viral hemorrhagic septicemia virus infections in Pacific herring. Dis Aquat Org 93:43-49

Hervé-Claude LP, Carpenter TE, Hedrick RP (2008) Risk of introducing viral hemorrhagic septicemia virus (VHSV) to the Chilean South Pacific via sardine imports from Europe. Dis Aquat Org 78:199-207 
ISO (International Organization for Standardization) (2010) Conformity assessment-general requirements for proficiency testing. ISO/IES 17043. ISO Headquarters, Geneva

Jonstrup SP, Kahns S, Skall HF, Boutrup TS, Olesen NJ (2013) Development and validation of a novel Taqmanbased real-time RT-PCR assay suitable for demonstrating freedom from viral haemorrhagic septicaemia virus. J Fish Dis 36:9-23

McCullagh P, Nelder JA (1989) Generalized linear models. Chapman \& Hall, Boca Raton, FL

Meyers TR, Short S, Lipson K (1999) Isolation of the North American strain of viral hemorrhagic septicemia virus (VHSV) associated with epizootic mortality in two new host species of Alaskan marine fish. Dis Aquat Org 38: 81-86

OIE (World Organization for Animal Health) (2009) Manual of diagnostic tests for aquatic animals, 6th edn. OIE, Paris

Phelps NB, Patnayak DP, Jiang Y, Goyal SM (2012) The use of a one-step real-time reverse transcription polymerase

Editorial responsibility: Mark Crane,

Geelong, Victoria, Australia chain reaction (rRT-PCR) for the surveillance of viral hemorrhagic septicemia virus (VHSV) in Minnesota. J Aquat Anim Health 24:238-243

> Phelps NBD, Goodwin AE, Marecaux E, Goyal SM (2013) Comparison of treatments to inactivate viral hemorrhagic septicemia virus (VHSV-IVb) in frozen baitfish. Dis Aquat Org 102:211-216

Shah R, Luo E, Fong CL (2009) A high-throughput workflow for the extraction of aquaculture pathogen DNA/RNA from aquatic tissues. American Association of Veterinary Laboratory Diagnosticians, 52nd Annual Conference, San Diego, CA, p 146

> VHSV Expert Panel and Working Group (2010) Viral hemorrhagic septicemia virus (VHSV IVb) risk factors and association measures derived by expert panel. Prev Vet Med 94:128-139

Warg JV, Clement T, Cornwell ER, Cruz A and others (2014) Detection and surveillance of viral hemorrhagic septicemia virus using real-time RT-PCR. I. Initial comparison of four protocols. Dis Aquat Org 111:1-13

Submitted: July 31, 2013; Accepted: April 29, 2014

Proofs received from author(s): July 31, 2014 